Volume 10 | Issue 5

December 2019

\title{
Colonial Legacies And Collaborative Action: Improving Indigenous Peoples' Health Care in Canada
}

Lloy Wylie

Schulich Interfaculty Program in Public Health, Western University, lwylie2@uwo.ca

Stephanie McConkey

St. Michael's Hospital, Unity Health Toronto, Stephanie.McConkey@unityhealth.to

Ann Marie Corrado

Women’s College Hospital, annmarie.corrado@wchospital.ca

Recommended Citation

Wylie, L., McConkey, S., \& Corrado, A. M.(2019). Colonial legacies and collaborative action: Improving Indigenous Peoples' health care in Canada. The International Indigenous Policy Journal, 10(5). doi: https://10.18584/iipj.2019.10.5.9340 


\title{
Colonial Legacies and Collaborative Action: Improving Indigenous Peoples' Health Care in Canada
}

\begin{abstract}
Indigenous people experience significant health disparities compared to non-Indigenous people, which are exacerbated by less accessible and poorer quality health care services. This research aimed to understand the specific barriers to health care that Indigenous patients and their families face, as well as to explore promising practices and strategies for improving the responsiveness of health services to the needs of Indigenous people. Through qualitative interviews with Indigenous and non-Indigenous health care and social services providers, we identified a range of challenges and successful approaches, and developed recommendations for improving policy and practice to address the gaps in culturally safe health care services. Our study shows that many of the barriers Indigenous people face when accessing health care are rooted in the broader social determinants of health, such as poverty, racism, housing, and education. These are complex problems that are outside of the traditional scope of health care practice. However, this study has also demonstrated that many barriers to equitable care actually stem from within the health care system itself. We found that health care gaps were often attributable to poorly funded on-reserve health care services and culturally unsafe off-reserve services. Attitudes and practices among those working in health care and gaps in coordination between mainstream and Indigenous services are challenges related to the way the health care system operates. Solutions are needed that address these issues. Given the multifaceted nature of access barriers, strategies to improve health services for Indigenous people and communities require a comprehensive and systemic approach.
\end{abstract}

\section{Keywords}

health care, Indigenous Peoples, qualitative research, health access, cultural safety, social determinants of health, medical education

\section{Acknowledgments}

We express our appreciation to Danielle Alcock, Jasmine Fournier, Jacqueline Kang, and Bimadoshka Pucan, who provided research assistance for this project. We would also like to thank the Indigenous community health care leaders who provided direction for this research, as well as the care providers, leaders, and Indigenous people that we interviewed. We would like to acknowledge Associated Medical Services for funding this research, which is part of the Engaging for Change project, funded as a Phoenix Fellowship from AMS.

\section{Creative Commons License (c) (1) (9)}

This work is licensed under a Creative Commons Attribution-Noncommercial-No Derivative Works 4.0 License. 


\section{Colonial Legacies and Collaborative Action: Improving Indigenous Peoples' Health Care in Canada}

Indigenous people's ${ }^{1}$ experiences of health and social disparities in Canada constitute both a health and social justice concern (Browne, 2017; Browne et al., 2016; Greenwood, Leeuw, Lindsay, \& Reading, 2015; Howse \& Dwyer, 2015). These disparities are rooted in both colonial history and ongoing oppressive policies and practices that perpetuate contradictory pressures of exclusion and assimilation (Browne, 2017; Germove \& Hornosty, 2012). In Canada, Indigenous people face significant health disparities and negative experiences with health care that demonstrate an urgent need to act on these inequities (Aboriginal Women's Health and Healing Research Group, 2005; Adelson, 2005; Reading \& Wien, 2009; Richmond \& Ross, 2009). Despite significant health care needs, research has shown that Indigenous people are reluctant to access health care services due to ongoing negative experiences (Allan \& Smylie, 2015; Blumenthal \& Sinha, 2015; Brian Sinclair Working Group, 2017; Browne, 2017; Browne et al., 2016; de Leeuw, Lindsay, \& Greenwood, 2015; Fohlich, Ross, \& Richmond, 2006; Germove \& Hornosty, 2012; McCallum \& Perry, 2018; Reading, 2015; Wylie \& McConkey, 2019). This research aimed to understand barriers to health care services as well as identify culturally safe practices and strategies for improving health care services for Indigenous people. In exploring these challenges in health care, it is first necessary to explore the broader social and political context in which it takes place.

\section{Colonialism, Systemic Racism, and Structural Violence in Health Care}

The barriers Indigenous people have in accessing health care are structural, established through historical events, perpetuated in current policy, and expressed in behaviours that all interact in ways that inflict violence on Indigenous people. Structural violence, where large-scale social and economic structures create and perpetuate the conditions of ill health and suffering (Farmer, 2004), is a concept relevant to this situation. The colonization of Turtle Island (also known as North America) and the eventual creation of Canada was an act of genocide that attempted to wipe out Indigenous Peoples who live in these territories (Amir, 2018; Matthews, 2019). Ongoing control and oppression continue through the policies within the Indian Act of 1876, which created the Indian reserve system-a system that continues to this day.

The Indian Act (1985) created the Indian Register, thus legally classifying some First Nations people as Status Indians based on criteria, such as ancestry and membership in an Indian band. This arrangement ensures that governance and services for First Nations people are under the jurisdiction of the federal government. Federal responsibility for First Nations health care in a health care system that is run by provincial governments sets the stage for significant jurisdictional gaps that undermine equitable access to health care for Status First Nations people in Canada (Indian Act, 1985; Lavoie, Browne, Varcoe, Wong, \& Fridkin, 2015).

\footnotetext{
${ }^{1}$ Indigenous Peoples of Canada include First Nations (Status and non-Status), Inuit, and Métis, distinct peoples with unique histories, languages, cultural practices, and spiritual beliefs (Government of Canada, 2018). The terms Aboriginal, Indian, and Native are also sometimes used in Canada to describe these distinct nations. In the text, Indigenous Peoples refer to multiple Indigenous communities, whereas Indigenous people refer multiple individuals.
} 
To overcome these systemic inequities, approaches to care need to address historic and ongoing inequities in power relations (Browne et al., 2016). Ongoing Canadian colonial policies continue this structural violence and genocide against First Nations people through the perpetual underfunding of basic infrastructure in reserve communities that results in poor health and health care (Browne, 2017; Germove \& Hornosty, 2012; Truth and Reconciliation Commission of Canada, 2015). Health and social programs for Indigenous people are often determined by population-level data such as the Census and other national data sources (Walter \& Anderson, 2013). This practice is extremely problematic because these data sources do not include First Nations people living on reserve and severely undercounts urban Indigenous people (Rotondi et al., 2017), in turn underfunding health and social programs for Indigenous people across the nation. The longstanding underfunding of services delivered on reserves limits the range of accessible health services and undermines the health and well-being of First Nations (Chambers \& Burnett, 2017; Senate Committee on Human Rights, 2009). Funding provided by the federal government to First Nations communities is allocated to specific programs, defined by the federal government, and thus may be out of sync with community needs (Richardson \& Murphy, 2018). Given the lack of a full spectrum of health and wellness services provided within First Nations communities, most First Nations people living on the reserve need to access mainstream health services, usually in an urban centre. Research in Canada has shown that mainstream services are often unwelcoming and hostile places for Indigenous people (Allan \& Smylie, 2015; Browne, 2017; McCallum \& Perry, 2018; Wylie \& McConkey, 2019). Status First Nations and Inuit can access provincial programs and services through coverage from the Non-Insured Health Benefits (NIHB) program, run by the federal government; however, eligibility for specific services is dependent on residency status (Reading \& Halseth, 2013; Senese \& Wilson, 2013). NIHB also provides extended medical coverage for some health care services provided by the federal government of Canada (i.e., Health Canada). Coverage may include prescription drugs, medical supplies, dental care, vision care, and medical transportation (Government of Canada, 2019). Non-Status First Nations and Métis are exempt from NIHB and therefore do not have access to the same services as Status First Nations and Inuit. Non-Status First Nations and Métis have access to the standard health coverage in their province or territory (Reading \& Halseth, 2013; Senese \& Wilson, 2013). Indigenous people who reside offreserve do not have the same access to federally funded health care programs and services (i.e., community or band-run health care services), while individuals living on reserve do not have the same access to provincially funded health care programs and services (i.e., hospital or at-home health care services; Snyder \& Wilson, 2012).

This two-tiered and divided system of health care for Status First Nations in Canada leaves people caught between a rock and a hard place, where on-reserve programs are underfunded and not comprehensive, and off-reserve services are often unwelcoming, culturally inappropriate, and lack an understanding of Indigenous people's experiences. Disrespectful treatment and the imposition of a Western model of care are symptoms of the systemic racism embedded in both policy and practice that negatively shapes Indigenous people's experiences, leading to significant barriers to health equity (Eby, 2007; Josewski, 2012). The unwelcoming environment in the health care system can make Indigenous people reluctant to access care and, when they do, they often encounter discrimination, negative stereotyping, and dismissal of their concerns (Wylie \& McConkey, 2019). The result is that Indigenous people face a lack of access to quality, comprehensive, and culturally appropriate health care, both within reserve communities and in urban health care services. Therefore, neither health system is meeting the complex health and wellness needs of Indigenous people, regardless of where they live and access health 
The International Indigenous Policy Journal, Vol. 10, Iss. 5

care (Benoit, Carroll, \& Chaudhry, 2003; Browne \& Smye, 2002; Browne, Smye, \& Varcoe, 2005; Ramsden, 1993).

The high burden of illness facing Indigenous people demonstrates a need for services that meet their requirements and incorporate knowledge of social and historical factors shaping experiences of disease (Hammod et al., 2017). Unfortunately, mainstream service providers often do not understand the issues that many Indigenous patients face in everyday life, such as poverty, racism, violence, and a lack of basic services such as clean water (Browne et al., 2005; de Leeuw et al., 2015; Reading, 2015). Individuals who are struggling with complex health, family, and socio-economic challenges often experience a disconnection in health systems that is sometimes expressed as a lack of empathy among health care providers. Indigenous people often do not feel safe, understood, or cared for within mainstream health care services. When health services are not safe or compassionate, Indigenous people tend to only access services in acute situations, rather than for preventive or early diagnostic care (Browne et al., 2010; National Aboriginal Health Organization, 2003). As Smylie (2000) asserted in a guide for health professionals, "In forging a balanced and positive health care practitioner-patient relationship, it is essential to understand the heritage context of the Aboriginal patient in order to negotiate chasms and find common ground" (p. 2).

Indigenous people value holistic care, which balances physical, emotional, mental, and spiritual health; yet many feel this approach is not respected within the mainstream health care system (Belanger, 2010; Chandler \& Dunlop, 2015; Dion Stout, 2015; Israel, Checkoway, Schulz, \& Zimmerman, 1994; Kirmayer, Simpson, \& Cargo; 2003; Makokis \& Makokis, 2015; Polanco \& Arbour, 2015; Scott, 2010; Stewart, 2008; Tagalik, 2015). Different models of care are needed that are relevant for the specific health needs and service preferences of Indigenous people and communities. The Nuka system of care, run by the Southcentral Foundation, an Alaska Native owned and community-driven healthcare organization, offers an effective model that has demonstrated improved health services and outcomes. The Nuka system is based on values of customer ownership, relationship-based care, powerful primary care, and whole system transformation that ensures same-day access to team-based compassionate care (Eby, 2019). Additionally, patient navigation approaches have also been identified as an effective way to facilitate appropriate access for Indigenous patients through building positive relationships (Whop et al., 2012). When navigators are from the Indigenous community and trained through community-led curricula, they have been able to support more effective Indigenous patient care journeys (Braun, Allison \& Tsark, 2008; Warren-Mears, Dankovchik, Patil, \& Fu, 2013). These models demonstrate a range of practices that can improve the health care experiences of Indigenous people-from a communitycontrolled model that promotes full system change to navigation supports that facilitate access and coordination across existing services. Solutions need to be tailored to specific contexts to ensure effective implementation.

\section{The Context of Reconciliation}

The Truth and Reconciliation Commission (TRC, 2015), which collected stories about abuses Indigenous people suffered as a result of colonial policies, has drawn national attention to Canada's ugly history of racism and genocide, and the ongoing oppression of Indigenous people. This reconciliation process and the national dialogue that it set in motion raised awareness of deep-seated issues stemming from racist colonial policies and practices. There is now greater awareness of the colonial roots of health 
disparities among Indigenous Peoples, stemming from intergenerational trauma, systemic poverty, poor community and social infrastructure, and high levels of interpersonal and structural violence.

The TRC's recommendations have renewed the call for a multi-faceted strategy to address the wide range of inequities faced by Indigenous people in Canada. One of the key TRC calls to action prioritizes the need to enhance cultural competency in health care and health education, with explicit recommendations that would require cultural safety training for health professionals as well as to increase the numbers of Indigenous health professionals working in the health care system (TRC, 2015). The context is right for systematically taking on the challenges of racism and discrimination in order to transform an exclusionary health care system into one that provides high quality, respectful, and compassionate health care for all Indigenous people.

\section{Methods}

\section{Research Aims}

This research sought to identify the systemic challenges in providing Indigenous people with quality, accessible health care. It also aimed to explore promising practices as well as elicit recommendations for supports and changes. Using a qualitative approach, we interviewed providers of health and social services, including Indigenous respondents, about their experiences with Indigenous people in the health care system. This article presents the perspectives of people working inside the system on the key barriers and facilitators to equitable access and quality health care. Respondents discussed both practicelevel changes, as well as policy recommendations for sustainable change, to ensure Indigenous people get the health care they need regardless of where they live or which level of government provides their health care coverage. The article then shares recommendations for meaningful change to ensure quality, accessible health care for Indigenous people. The article also reflects on the policies and practices of structural violence that perpetuate discrimination and exclusion and presents solutions that both Indigenous and non-Indigenous health care providers feel will disrupt those norms and produce meaningful change.

\section{Study Design}

The project, Engaging for Change: Coordinated Strategies for Improving Health Services for Indigenous people, began with the understanding that health care services were not meeting the needs of Indigenous people in Canada, regardless of whether they were living on reserve or in an urban centre across the country. The first author had experience with the health system in British Columbia, where there is a new Tripartite Framework Agreement on First Nations Health Governance between federal, provincial, and First Nations political leaders that aims to tackle health inequities faced by First Nations people (Minister of Health [Canada], Minister of Health [British Columbia], \& First Nations Health Society, 2011). Although the partnerships were sometimes tense, there was a recognition of reciprocal accountabilities, and shared responsibilities and mandates among the players, including health care organizations, such as regional health authorities and hospitals, to address the negative experiences of Indigenous people (O’Neil et al., 2016). The context in Ontario was quite different, where little attention was given to improving the experiences of Indigenous people in the health care system. The first author therefore initiated the project to delve into the Ontario experience in order to understand the knowledge and commitment to Indigenous heath equity in this context. Engagement between the 
first author and Indigenous health professionals working as health directors, managers, and support staff in both First Nations communities and urban centres in Southwestern Ontario identified many concerns. To begin, Indigenous health professionals highlighted poor quality and a lack of continuity of care for Indigenous people. Indigenous health professionals felt there was a general lack of appropriate and compassionate care for Indigenous people. The main problems included little engagement between health professionals and Indigenous patients and their families; limited, if any, coordination between mainstream and Indigenous-run health services; a lack of follow-up care and effective discharge planning; inadequate focus on equity in health services; and an unwelcoming environment. They suggested that research was needed to further explore their concerns, understand the basis of these challenges, and identify how the health care system could improve the care provided for Indigenous people.

Indigenous health care providers noted five priority areas including emergency services, diabetes, maternity, cancer, and mental health. Among Indigenous patients, there was high usage of health services in these areas and often problematic experiences. The research project was initiated in 2014, focusing on experiences in providing care to Indigenous patients in these five priority areas. Indigenous and non-Indigenous care providers in hospital, public health, and community-based health services were interviewed. The research was carried out in two phases: The first phase focused on interviews with health professionals in mainstream services and the second phase focused on expanding the range of participants to include more Indigenous people working within health and social care, both in mainstream and Indigenous-run services. There were two Indigenous participants in Phase 1 and six in Phase 2. Some of the participants identified that they were from one of the First Nation communities surrounding the city where the study took place. Some identified which Indigenous community they were from or affiliated with, but not all shared their nation, clan, etc. To reduce the risk of participant reidentification, we will not be sharing the names of their nation or clan. This project makes a unique contribution by bringing in the perspectives of front-line care providers and privileging the insider knowledge of Indigenous people working at the interface between Indigenous people, communities, and the health care system. The research was approved by the Health Sciences Research Ethics Board at Western University and by the ethics review process of the health sciences centre responsible for the hospital and community-based clinics.

\section{Theoretical Framework}

The research was informed by critical theory, which focuses attention on the broader social, political, cultural, and economic values (Lincoln, Lynam, \& Guba, 2011) that underlie the experiences of both Indigenous people accessing health services, and the people working within those health care organizations. Following the analysis of structural violence, this research focused on the broader social, economic, and political context in which health care reconciliation could take place. Critical theory and Indigenous methodology were best served through qualitative description, which helped us understand the complex systemic issues that affect Indigenous people's experiences in health care. This approach is particularly valuable for Indigenous health research because it facilitates respondents' use of narratives and storytelling, a traditional way of sharing information and knowledge (Laycock, Walker, Harrison, \& Brands, 2011). Semi-structured interviews supported participants in drawing on their experiences and sharing their stories through conversation with researchers. While semi-structured interviews are a 
rigorous method to collect qualitative data, they are additionally relevant for Indigenous participants, as the process builds a relationship between the participant and researcher (Laycock et al., 2011).

\section{Participant Selection}

This study employed purposive sampling to recruit participants who hold rich information "by virtue of having direct and personal knowledge" (Sandelowski, 1995, p.180); yet, it also allows the researcher to explore maximum variation (Lincoln \& Guba, 1985; Sandelowski, 2000). Health care provider participants were selected based on their experience working in one or more of the five priority health service areas and their experience in providing service to Indigenous people. Indigenous care providers also had experience as advocates for Indigenous patients, having experience with health care services for themselves or a family member, friend, or client. Participants were approached in person or by phone and then sent an email introducing the project and team in more detail. In Phase 1, participants included health care providers and decision makers working in emergency, maternal, mental health, cancer, or diabetes care across hospital, public health, and community-based health services in a large city in Southwestern Ontario. Respondents came from a variety of specialties, including physicians, nurses, social workers, patient navigators, patient experience specialists, and departmental leaders, in order to represent the range of health professionals working within the system. In Phase 2, additional Indigenous participants were recruited from within local health and social care services, in both mainstream and Indigenous-run organizations in order to expand the scope of knowledge and bring in more Indigenous voices from within the system. Indigenous respondents spoke from both their professional and personal experiences as patients, caregivers, care providers, and advocates within the health care system. Respondents were selected based on their involvement with various initiatives aimed at improving health care for Indigenous people within the city and local reserve communities. The majority of the respondents were women. A total of 31 people were interviewed, including 8 Indigenous respondents $(2$ working for mainstream organizations and 6 working for Indigenous organizations with roles that interfaced with mainstream health services), 1 non-Indigenous respondent working for an Indigenous organization, and 22 non-Indigenous respondents working for mainstream health and social care organizations.

\section{Data Collection}

All interviews were carried out by the first author, a woman with a background in Indigenous health research and practice, working as an assistant professor in a health field. Many of the interviews also included one of the Indigenous female graduate student researchers on the team. Respondents selected the location for their interview, including their place of work or at the office of the researcher.

Interviewees were given information about the purpose of the research, and then they were asked 20 indepth questions about the positive and negative experiences that they saw during interactions between health care providers and Indigenous patients within health care settings. Questions were related to awareness about Indigenous-specific health access barriers, perspectives and understandings of Indigenous health and wellbeing, and knowledge of and referrals to existing supports available to Indigenous people in the city and surrounding area. Interviews and focus groups were audio recorded, transcribed verbatim, and anonymized. 
The first data collection phase (completed in 2015 and 2016) focused on health professionals, where 25 individuals participated in semi-structured interviews $(n=21)$ and two group interviews with two participants each $(n=4)$, which lasted 1 to 1.5 hours. Two of the health provider respondents who participated in one-on-one interviews identified as Indigenous. The second phase focused exclusively on interviews with Indigenous people working in health and social care in order to add more Indigenous voices to the sample, for a total of 8 Indigenous respondents. These interviews took place from 2016 to 2018 and included a group interview at an Indigenous-run organization $(n=4)$ and one-on-one interviews $(n=2)$. The researcher engaged with representatives from several local and regional Indigenous health and social service organizations to share and discuss emerging themes to ensure they appropriately reflected common challenges and collective priorities. All respondents were sent copies of the summary reports, including a 5-page report with a detailed summary of the key findings and a single page infographic that encapsulated key findings. Respondents were encouraged to reach out to discuss any concerns. The researcher met with Indigenous representatives to review their transcripts, discuss the analysis of the findings, and approve the use of their quotes in this article.

Relationship building is key in Indigenous health research (Wilson, 2008), as there is a history of mistrust between academics and Indigenous communities that continues into the present (Castleden, Sylvestre, Martin, \& McNally, 2015; Cochran et al, 2008; Smith, 2013). Developing trust within relationships can increase the quality of the research and ensure that it is guided by community priorities (Laycock et al., 2011). As a result of the ongoing relationship between the researcher and Indigenous community organizations, this research has continued into the next phase, which involves collectively addressing health system barriers.

\section{Data Analysis}

The data was coded on NVivo 10 Software using inductive thematic analysis (Braun \& Clarke, 2014) by three researchers. The coding tree emerged from the data in each of the lines of questioning (experiences, resources, relationships, etc.; Elo \& Kyngäs, 2008; Hsieh \& Shannon, 2005). The team discussed emerging codes in order to achieve triangulation (Bowen, 2008). The coding of transcripts from Phase 1 ceased when data saturation was reached, "when nothing new is being added" (Bowen, 2008, p.140). All codes from Phase 1 were then reviewed in order to interpret the data and sort it into clusters to generate themes and sub-themes based on their meanings and relationships to one another (Dey, 1993; Hsieh \& Shannon, 2005). Preliminary data from Phase 2 was coded to identify any new themes and add to the existing understandings of challenges, facilitators, and recommendations for change.

\section{Results}

The data showed there are many barriers that Indigenous people face in accessing health care services, as well as promising practices to mitigate or overcome these barriers. Respondents identified many barriers to health care stemming from both within and outside of the health care system. Respondents had a variety of recommendations to change the health care system in order to provide better care for Indigenous people (See Table 1 for an overview of all themes and sub-themes). 
Wylie et al.: Colonial Legacies and Collaborative Action

Table 1. Themes and Sub-themes

\begin{tabular}{ll}
\hline \multicolumn{1}{c}{ Themes } & \multicolumn{1}{c}{ Sub-themes } \\
\hline Barriers to health care services & Social determinants \\
& Provider attitudes and relationships \\
& Health system barriers \\
Promising practices & Building relationships \\
& Cultural safety and community-based training \\
& Connecting with services and transition supports \\
& A desire for improvement \\
Participant recommendations & Increase knowledge \\
& Increase Indigenous-specific supports \\
& Service coordination through navigation supports \\
\hline
\end{tabular}

In summary, many participants spoke about the social determinants of health, such as poverty, rural isolation, physical environments, and racism, having an adverse impact on Indigenous people's health, as well as creating barriers to accessing health care. In addition, respondents identified negative provider attitudes, such as stereotyping and blaming, that result in mistrust and poor relationships with Indigenous people, thus creating additional access barriers. Indigenous respondents spoke of the different access barriers in on-reserve and off-reserve communities, as well as barriers for those relying on NIHB coverage. In Phase 1, jurisdictional barriers were discussed. There are ongoing disputes between the federal government and provincial governments over who has fiduciary responsibility for Status First Nations and Inuit health care. One participant shared their experience as an Indigenous patient navigator in which they were unable to get supports to provide necessary care for a patient on reserve because the provincially funded health services in the local city would not provide care on reserve. The city health centre claimed that on-reserve services were the fiduciary responsibility of the federal government. Other respondents spoke about the challenges of accessing funding for health care they needed through Jordan's Principle, ${ }^{2}$ which says that whichever level of government is first billed for health services will pay and then seek reimbursement from the other level of government if the patient is a child that falls under their jurisdiction. Respondents shared examples where First Nations people had to pay out of pocket for health care services and supplies, and their claims had been rejected through the Jordan's Principle funds, even though it was for eligible expenses.

A number of participants in Phase 1 also identified that they did not know which services were provided by NIHB (federal health care coverage for Status First Nations and Inuit). Moreover, most participants were unaware of which services were covered for non-Status First Nations or Métis individuals, and

\footnotetext{
${ }^{2}$ Jordan's Principle is intended to ensure that First Nations children do not experience delay, denial, or disruption of services because of jurisdictional disputes (for an analysis of this policy, see Blumenthal \& Sinha, 2015).
} 
which health care services could be provided on-reserve versus off-reserve. Of those who were aware of NIHB funding, they noted that this program did not cover supplies or medications to the same level as the provincial system, which meant that patients had to return to the hospital more frequently. Some physicians were also aware of how Indian Status impacts access and NIHB coverage. Most respondents spoke more generally about Indigenous people, rather than differentiating between First Nations, Inuit, and Métis, although many noted that the access challenges were greater among people living in First Nation communities compared to their counterparts living in the city.

In terms of promising practices, respondents spoke about the importance of building community-based relationships between Indigenous people and health care providers, the benefits of training in cultural safety, the positive outcomes associated with connecting Indigenous patients with community services and transition supports, and the desire many health care providers have for improving Indigenous people's experiences. This suggests that, although currently there are significant problems within the health care system, there is great potential to advance improvements that will ensure access to quality and culturally safe care for Indigenous people.

\section{Barriers to Health Care Services}

Respondents identified a range of barriers Indigenous people face when accessing health care, including those stemming from social determinants of health, negative health care provider attitudes, poor patient-provider relationships, and problematic issues within the health system around coordination and follow-up care.

Social determinants. Health care providers demonstrated an awareness of various ways that social determinants of health limit Indigenous people's access to health care. The most common barrier noted was poverty, specifically the inability to afford transportation. First Nations people living in reserve communities were seen to have the greatest health care access barriers, with notably poorer access to primary care. A family physician stated that if their patients "live on the reserve, they have to get into the city to get care, whether it is in the hospital or specialty clinics, and transportation can be an issue" $(\mathrm{H} 23 \mathrm{P})$. A manager in women's health shared that to access some services that require frequent appointments, such as obstetrics, meant that people had to travel long distances without their support systems on a regular basis, "which can be an expensive undertaking, to come to the hospital or arrange transportation or for them to arrange daycare for their other kids" (AO3L). As a respondent from an Indigenous community agency noted, many Indigenous people with health issues are struggling:

Exhausted from dealing with everyday life. At the thought of having their hydro being cut off... Food security, housing security, all that pressure. And then to have that energy to advocate for a loved one or family one takes an enormous amount of mental stamina. If you are already pounded down by life in general, then that takes a lot of energy ... It is too hard to deal with life in general, then to have an added burden to care about a special-needs child or access services. (FG01)

Respondents also expressed that there is a general lack of knowledge among health care workers as a whole regarding the broader challenges faced by Indigenous patients. A leader in the health care system identified this gap in knowledge and its implication in interactions between patients and providers: 
I would say the first challenge being recognizing the differences in needs. That core understanding of some of the different social determinants of health and how they influence a population. I would say there is not a lot of appreciation for some of the challenges that Aboriginal people face and where that might stem from. That lack of understanding has not always contributed to the best relationships. (H06L)

As a result, health care providers make assumptions about what Indigenous people should do, particularly around "healthy" behaviours. A family physician noted that Indigenous patients are often blamed for their poor health, especially after they have been given advice about health behaviours:

I know I have told you to monitor your sugars, what happened? Are you eating well and then the patient says, "Oh, I can't afford good, healthy food. It's expensive, so I can only afford starch or eating pasta, I can't afford to buy vegetables.” (AH11P)

This physician also noted that the precarious housing arrangements many Indigenous people have created a significant challenge to follow up: "They don't have phone numbers even. Unless they come and see me, I have no means to trace them ... even when there is something wrong with the bloodwork" (AH11P).

Health care provider attitudes and relationships. Several health care respondents admitted that neither they nor their colleagues were trained in cultural competency or cross-cultural communication. Many identified challenges in developing positive relationships of trust with Indigenous people in their care. Non-Indigenous respondents noted a general lack of awareness of Indigenous history, cultural practices, knowledge systems, perspectives of health and wellbeing, and traditional medicines and healing practices. As a physician working in diabetes care noted, "We don't really understand the issues that people are coming from or why they are different from what we have been taught from our standard educational tools and textbooks" (A13P). As an Indigenous respondent stated:

They just look at us and see all the friggin' negatives. They see all the stereotypes. They look at us and think, "They are all the same, they are just drunk, they are just drug addicts" ... You can be dressed nice all the time and still be accused of things. (FG01)

Health care providers also noted that widespread discrimination combined with this lack of understanding often leads to mistrust. When Indigenous people do not trust health care providers, they tend to not articulate their health issues and they are more likely to discontinue health care services prior to the completion of their treatment (B21LP). As an Indigenous respondent shared, "The only time I ever go to the hospital or seek any kind of help is when I think that I am dying, because I know that they don't care about anything else" (FG01). In addition to limiting service use, bad experiences in health care negatively impacted appropriate follow-up and referrals.

Health care providers admitted that mainstream health care practices and norms differ from Indigenous perspectives and practices. As such, relationships between patients and providers could become strained, as a family physician noted: "Particularly in Aboriginal communities where understanding their culture in mainstream society has been a challenge" (AH11P). Indigenous and non-Indigenous health providers alike noted that in addition to poor understanding, Indigenous medicines and healing practices were not valued or respected in the conventional health care system. As one Indigenous respondent shared, 
“Don't think that Native people don't feel the attitude through [health providers'] words, and their stance and their behaviour... We're gonna do whatever it is that we need to, to protect our family members ... It's still scary" (CR6S).

Respondents shared that the establishment of trusting relationships between Indigenous people and care providers is critical. A physician working in emergency medicine noted that Indigenous people require "long-term, consistent, trusting relationships with people [health providers] that they respect" (A04P). In addition, health care providers discussed the urgent need for physicians to give Indigenous people more time to speak and share their health issues during appointments. A leader in the hospital stated, "we don't make it easy for [Indigenous people] to speak up ... We don't give them permission or invite them to do so" (A08L). Respondents identified that Indigenous people tend not to articulate their health problems because they are afraid to ask questions, fearing the judgement of care providers.

Respondents advocated for health care providers to give Indigenous Peoples more time to ask questions in an inviting environment. A patient support staff member shared that physicians need to engage in dialogue with Indigenous Peoples that "allow more reflection, contemplation, discussion, and questions" (A20S). This additional time will result in more appropriate care because recommendations will be based on shared understandings of the problems and priorities. Indigenous people would feel more comfortable with their physician's recommendations and thus are more likely to be able to follow their physician's advice, if it comes from a relationship and a place of understanding.

Health system barriers. The structure of the health care system itself is a barrier, as navigating the system can be challenging. This is even more complicated for Status First Nations people, who have to navigate and piece together federal, provincial, and band-run services. The use of medical jargon also creates misunderstandings and limits patients' ability to have a say in their care. Many respondents felt that Indigenous people often do not get the full range of services that would be considered standard practice. Some physicians will not take on Indigenous patients. As a family doctor shared, some physicians "go 'wow, you are pretty complicated. I don't really want to get involved with you.' And so that exacerbates the whole doctor shortage" (H23P).

Policies were seen as a potential barrier in ensuring access and appropriateness of health services for Indigenous people. As a leader in the health care system shared:

There were some policies that actually, I would say contributed to poorer care. For example, not allowing smudging was an issue for a lot of families. There is also issues around how a body was cared for after a person had been pronounced dead. There's also issues around the inability for families to gather in a hospital room or even have any space within the hospital to accommodate families. (H06L)

Respondents identified significant gaps in follow-up care. For instance, as an Indigenous respondent shared, "Why do they never do follow up appointments with anybody ... There was no other appointment for her to see how it went or anything" (FG01). A leader in cancer care explained that extra effort was needed to ensure proper follow-up care was in place for Indigenous people (A02L).

Despite these efforts, many Indigenous people were not getting follow-up care due to jurisdictional issues and systemic challenges. A leader in women's health care noted that the community care access 
centre (CCAC), which was responsible for coordinating home and community-based care, would not provide care on reserve for First Nations patients leaving the hospital (A03L). Difficulties during transition, which encompassed unclear communication, post-discharge issues, and inadequate liaison, undermined coordinated care. A family doctor noted that there was a general "lack of awareness of not just cultural needs, but... [that it's] the health care system that is failing First Nations” (H23P).

Uncoordinated care post-discharge led to negative experiences for Indigenous patients. Health care providers described that ensuring follow-up care was not a standard protocol. As a women's health care leader stated:

If you have a baby here and you haven't had any complications and you did a vaginal delivery, you're here for less than 24 hours. We send you out and we hope that you have been connected with the right supports while you were here. (A03L)

Furthermore, health care providers identified poor communication within the regional networks that were meant to coordinate home and community care. Some respondents noted that they were able to get CCAC to provide home care, but when they did, it was poorly coordinated. When Indigenous patients "come home from hospital to community, that's where the disconnect is, because the discharge planner or CCAC for whatever reason, they don't notify home and community care” (H05S). Indigenous respondents were keenly aware of those gaps:

There is a plan in place but sometimes the plan is not followed. Because they said they were going to set up ... whoever is supposed to be coming out to the reserve. And that wasn't set up for three days. And my dad's bandage did not get changed for three days after his surgery... They were like "you should have someone there by tonight to change it for you." And nobody came so I changed it for my dad. (FG01)

Many Indigenous respondents reiterated that the lack of care from the health care system meant that family members had to take on care responsibilities.

\section{Promising Practises}

Despite this range of barriers, respondents were able to identify some positive practices in providing care for Indigenous patients. The building blocks for positive health care experiences for Indigenous patients included trusting relationships, completing cultural safety and community-based training, connecting services, ensuring transition supports, and a desire for improved quality of care.

Building relationships. Relationship building between health care providers and Indigenous people was seen as one of the most successful strategies for creating a welcoming health care system. Positive interactions are more likely when trust is established by taking the time to build a respectful relationship. As a physician noted:

I think it is the trust building, I think that's the biggest thing and sometimes that goes well, and other times it doesn't. There's no easy way and as I say, it takes time and communication. It takes being with them when they have a need and try to meet it. (A07P) 
An emergency physician noted that this relationship can help put patients at their ease: "We were joking around quite a bit through his emerg [emergency department] stay and he wasn't feeling so anxious about his contact with the medical services as a result of that" (A01P). Indigenous respondents also emphasized the value of building relationships to ensure better care:

The relationship piece is huge. Because it is really getting to know people ... Even just knowing things like when they have certain appointments ... if they have home care, knowing what hours of the day that happens so that you can schedule around that. If they have special things like social events that they do... If they have to go for special treatments on a regular basis, you know what days of the week that is scheduled ... It's knowing their long medical and social history... It is that relationship piece, and people will want to be able to share with you what support that they need. (CR5S)

Cultural safety and community-based training. Many care providers also expressed the value of the Indigenous Cultural Safety Training Program, called San'yas, that had recently been initiated with hospital staff. The 8-hour online training program raised awareness of issues that were new to many care providers. As a psychiatrist shared, "I know a couple who found it really helpful as did I" (AB10P). Community-based training was also seen as valuable to build an understanding of the context of Indigenous people's lives. As an emergency physician shared:

When I was in medical school many years ago I went to [a small town] in Northern Ontario and that was probably my most valuable clinical experience with meeting and treating the Aboriginal population ... Many of the family doctors would helicopter out to the surrounding reserves and as a medical student you would participate in that. And it was very shocking to me at that time. I remember the lack of care and the rampant different conditions on the reserves. So, I was not aware previously from my med school training about that. (A01P)

The few physicians who did training in remote Indigenous communities noted that they never forgot the experience, and it helped them gain insight into the realities facing their Indigenous patients. These physicians expressed the dire need for more community-based training in order to train health care practitioners that provide better care for Indigenous patients.

Connecting services and transition supports. Some physicians identified supports for addressing health care needs of Indigenous people, including patient navigators and community-based services, such as local Aboriginal Health Access Centres. Physicians also noted that connecting patients to traditional healing has positive results and try to make space for cultural practices and family gatherings within the hospital space (AB10P). Many saw social workers and transition case managers as key liaisons between the health system and community supports. A manager in cancer care stated, "The social workers would have a good sense of what resources are available ... the communication is between the social workers and the patient navigator" (A02L). Indigenous respondents also identified the value of social workers in helping health care providers link Indigenous people with community-based services: "Social work usually is really good with knowing who to contact. But the medical teams aren't always aware of what services there are, so they rely heavily on social work to tell them" (CR5S). Coordination between acute and community-based services is seen as an important practice to ensure that Indigenous people have good continuity of care. 
A desire for improvement. Despite the lack of knowledge and skills in providing culturally appropriate care, attitudes among health care providers demonstrate a desire to improve their ability to meet the needs of Indigenous patients. Respondents expressed an eagerness to coordinate with community-based agencies, although they were uncertain of the services available and to whom to reach out. Participants wanted more resources, such as Indigenous liaisons and/or navigators, culturally appropriate materials (e.g., pamphlets, posters), and a list of contacts (e.g., Indigenous health experts) they could access when they needed supports for an Indigenous patient. Most respondents were willing to participate in cultural safety training, noting that they wanted to gain skills to help them better meet the health care needs of Indigenous people.

\section{Participant Recommendations}

All participants had recommendations on how to improve the health care system to ensure that Indigenous people get appropriate, culturally safe access to high quality health care services. The recommendations from both Indigenous and non-Indigenous health care providers focus on three main themes: increase the knowledge of health care providers about colonial history and its ongoing impacts; provide specific policy, programs, staff, and supports to facilitate Indigenous Peoples' access to health care; and improve coordination and navigation through health services across hospital and communitybased services.

Increase knowledge. All respondents expressed a desire for more training, and health care providers specifically wanted training that would give them concrete tools to improve their skills and practices in order to work effectively with Indigenous patients. Study participants emphasized the need to teach the history of colonization in Canada, including about the Indian Act and Indian reserves, to raise awareness about ongoing, systemic racism in federal policy. Indigenous respondents specifically emphasized the need to provide information about the impact of colonial policies and practices on Indigenous people and communities today. An Indigenous respondent who encouraged their colleagues to take a cultural competency course shared:

By providing them the whole historical background where First Nations people have come from and where they are today, I think it was a real eye opener. My colleague even said, I am so sorry, I didn't know and I didn't understand. (H05S)

Indigenous people emphasized the need for specific training about local communities: "There's an assumption Indigenous cultural competency is a blanket. If you have done it once then you understand all the needs of the Indigenous population of everyone across Canada" (FG01). A family physician emphasized that knowledge about the local Indigenous communities is essential: "Where they come from, what are the main health needs in the community, what are the barriers, what are the challenges" (AH11P). Health care providers need to know about the different cultures and issues specific to each of the Indigenous communities in the area they serve. Having knowledge about local Indigenous communities was also a recommendation from an emergency physician, who suggested that the medical schools should identify "reserves in the more immediate area surrounding academic schools and residency training... so that people get a better idea of how health services function close by or on reserve specifically and get a better idea of the interactions and the access and how things actually work" (A01P). 
Increase Indigenous supports. A number of recommendations were made about how to increase specific supports for Indigenous people to improve their experiences in health care. Addressing financial barriers can be done by providing transportation supports, as well as food for family members visiting the hospital. An Indigenous respondent identified a comprehensive approach to make a more inclusive space:

Have somebody who has cultural knowledge, who's a cultural helper, understands the history, go work in those hospitals. More than one. You need to have male and female, because that is the balance of the way that we are in the world. And them work together to help the rest of that system. And it doesn't mean just helping Native people it means helping all people ... How different that would be. (CR6S)

Other respondents emphasized the need for more Indigenous staff working in the hospital, specifically noting that having one person was not enough. Some suggested having someone on each floor so that they were available any time (FG01). Respondents felt that Indigenous people need to be in multiple roles throughout the institution, and they need to have space for traditional healers and ceremonial practices. The hospital needed to accommodate large families so they could gather around their loved one in care, particularly at the end of life.

Lastly, respondents identified the need for policies within the health care system to support culturally safe care. Mandates for training as well as standards for practice would be valuable to ensure that the process moves beyond just words to action. At the same time, respondents acknowledged that policy is not always put into practice; therefore, accountability processes need to be put into place:

Repercussions if you do not treat everybody equally... There should be some kind of policy in there ... because there is racism in the hospitals big time ... There is racist people on your staff that are dealing with everybody... So everyone who comes through that door deserves the same health care. (FG01)

Service coordination through navigation supports. Respondents shared that coordination could be improved if Indigenous people had dedicated liaison staff to work closely with families and to help navigate their care plan. An obstetrician suggested to "have a liaison within their own communities, aware of the issues and can counsel them outside of their appointments" (A09P-FG). Health care providers also felt that an Indigenous community liaison would be beneficial in communicating important information about the Indigenous patient to their health care providers, which would improve their care. A leader in family medicine suggested:

[It would be helpful] if there was someone who was a point person from the community, almost the liaison or that navigator type of person, who would liaise with the hospital, with the clinic and whether it was interpretation services or just sharing something personal about this person, about how you need to approach working with them. (A18L)

All respondents felt that having Indigenous staff would be the most effective approach to ensure appropriate, timely, and high-quality health care for Indigenous people. Community members, who are aware of local community health and wellness issues, should accompany Indigenous people throughout their care journey to provide information and support. This navigation role is essential for effective 
communication due to ease in building trust: "There's an instant connection with Native people ... A Native person is gonna tell a Native person a lot more than they're gonna tell a White person. No matter how nice you are" (CR6S).

Therefore, navigators can ensure Indigenous patients are able to talk through their issues and share the desires and values important to their care. The navigator would be positioned to ask questions during the appointment, specifically to ensure the care team explains everything and that families are involved in the development of the care plan.

Ensuring effective knowledge sharing and clear communication is essential for creating patient-centred care. Unclear or little communication disempowers families. As one Indigenous respondent asserted:

[It is hard ] when [care providers] come in and do all the stuff and don't tell you anything. 'Cause we wouldn't even know what questions to ask, right? .. Y You need to explain what you're doing ... no matter how small or how big ... it's important to the family members around that person. (CR6S)

Health care providers believed they were not giving Indigenous patients enough notice before discharge from hospital. As a result, patients, their families, and support services were not prepared. As one patient support staff shared:

Indigenous people don't get enough lead time or warning of discharge ... The team may communicate that they intend to discharge somebody at a certain time, but they are not making it as clear as it needs to be so that the patient and their families anticipate it. So, it can seem abrupt and without any prior warning. (A20S)

Moreover, health care providers shared that information about post-discharge supports was unclear, resulting in underutilization of resources and fragmented care. Providers need to tell Indigenous people "about the home and community care programs, so they will connect with them when they go home" (H05S). This meant that hospital-based services need to coordinate with community-based services, both on reserve and in urban centres. The navigation role would ensure effective and coordinated planning, so that resources and supports needed were in place.

\section{Discussion}

This research aimed to identify systemic challenges in providing Indigenous patients with quality health care, drawing on knowledge from Indigenous and non-Indigenous people working in health and social care settings. What was clear from this study is that there are significant barriers in access to care for Indigenous people. Status First Nations people experience additional barriers due to jurisdictional gaps, which have created ambiguity regarding the level of government that is responsible for delivering health services. A report from the Standing Committee on Indigenous and Northern Affairs Canada (2018) summed up the key challenges:

Currently, the responsibility to provide health care on reserve is unclear, and the provision of those services is currently shared among the federal and provincial governments, First Nations organizations and communities, and third-party services providers, resulting in a complicated 
and ambiguous framework. Because both levels of government are "passing the buck," First Nation communities have trouble obtaining the support they need to offer health care services on and off reserves. (p. 1)

Governments in Canada have imposed colonial control over First Nations health, while at the same time shirking their responsibility to ensure quality, comprehensive care. These jurisdictional divides demonstrate the systemic issues that undermine the ability of First Nations on reserve to access the full spectrum of health services that are available to all Canadians. Transformational change to promote First Nations' control over their health services can better ensure that First Nations people get the health care they need. There are some examples of this in Canada, including the First Nations Health Authority in BC, and the charter agreement with the Nishnawbe Aski Nation in Ontario (Richardson \& Murphy, 2018).

A trilateral agreement in 2011 between BC First Nations and the Government of British Columbia and the Government of Canada created a framework agreement to increase First Nations control over health services delivery (Minister of Health [Canada], Minister of Health [British Columbia], \& First Nations Health Society, 2011). This agreement transferred responsibility for federally run health services to the BC First Nations Health Authority (FNHA), and it required that the BC Ministry of Health work with First Nations to address health service gaps (Lavoie et al., 2016; O’Neil et al., 2016).

In Ontario, a tripartite agreement between the Canadian Ministry of Health, the Ontario Ministry of Health and Long-Term Care, and the Nishnawbe Aski Nation (NAN) resulted in the signing of the Charter of Relationship Principles. The aim of the Charter is explicitly to create a "responsive and system-wide approach to health for the NAN territory" in Northern Ontario (Government of Canada, Government of Ontario, \& Nishnawbe Aski Nation, 2017, Article 1.0). The agreement aims to enhance equitable access to culturally safe care throughout NAN territory. It echoes the commitment of Jordan's Principle to not let jurisdictional gaps or uncertainties about financial responsibility prevent timely access to health services.

These agreements demonstrate policy commitments to systemic change in health care that aim to address the types of jurisdictional issues raised in this article. On the ground, change often is a longer process than the creation of agreements, and implementation challenges and resource constraints mediate the way such commitments roll out. In BC, it took time to create the connections among frontline care providers, but the high-level commitments set the stage to facilitate these connections (O’Neil et al., 2016). The Charter agreement in Ontario was to start by reviewing the needs, prioritizing the actions, and developing an implementation and evaluation plan with shared responsibility for action.

The provincial governments in $\mathrm{BC}$ and Ontario have changed since these agreements were signed, and thus priorities and implementation approaches are also likely to change. Given the significant health system gaps, such as poor linkages between acute and community-based care, system integration and coordination will take effort and resources to overcome. Even with the best of intentions, health care transformation is a journey that will take time and commitment from all players. It is important to remember that policy goals need to ensure meaningful outcomes in health care practice that result in tangible improvements in Indigenous people's health care experiences. These gaps in health care have created the incentive for new First Nations health governance models. At the same time, First Nations 
people will continue to access care from mainstream health services and, therefore, those services need to address their discriminatory practices that create barriers to accessible and quality health care.

Our study has shown that respondents identified barriers rooted in the broader social determinants of health, such as poverty, racism, housing and education. These are complex problems that are outside of the scope of health care practice. However, this study has also demonstrated that many barriers to equitable care actually stem from within the health care system itself. Attitudes and practices among those working in health care and gaps in coordination between mainstream and Indigenous services are challenges related to the way the health care system operates. Solutions are needed that address these issues. Given the multifaceted nature of access barriers, strategies to improve health services for Indigenous people and communities require a comprehensive and systemic approach.

The lack of continuity of care is linked with experiences of racism and discrimination within the health care system (Allan \& Smylie, 2015; Browne et al., 2010; National Aboriginal Health Organization, 2003), and our study has confirmed this. Therefore, addressing racism, both implicit and explicit, must be a key part of the solution. Additionally, a holistic approach guided by Indigenous people is needed to ensure respectful care is based on Indigenous people's needs and preferences. Change is needed that goes beyond just re-modeling the existing health care practices of mainstream services (Benoit et al., 2003; Lallo, 2014; National Aboriginal Health Organization, 2003). This process of reconciliation within health care requires the identification of measurable targets for change.

All respondents identified that current norms and practices within health care undermine patientcentred and culturally safe care. Indigenous people had significant insight into the nuanced ways those barriers play out depending on culture, identity, geography (both on and off reserve), as well as socioeconomic status and educational attainment. All Indigenous people in this study shared experiences of racism and discrimination within the health care system. Many also shared examples of ways that they support Indigenous families as advocates and navigators within the health care system.

The results demonstrate that many health care access barriers facing Indigenous patients can be addressed through a culturally safe approach that ensures respectful behaviours of health care providers combined with supports and partnerships to improve the continuity of care. There is both a need and an appetite for improving the ability of the health care system to meet the needs of Indigenous people.

Respondents felt that all health care providers should go through Indigenous cultural competency and safety training. There needs to be mandated training on Indigenous health and wellness, and on the true colonial history and its impacts on Indigenous Peoples. The initiatives cannot just be a one-off tick-box of completing an online training module. Developing accreditation standards that align with equity and cultural safety within health professional education and continuing professional development programs can ensure that the training informs specific competencies in practice. Additionally, policies that perpetuate oppression and social exclusion need to be replaced with ones that advance equity and inclusion. Meaningful change will require commitment to an ongoing journey of learning, based on engagement with local Indigenous communities. An important start is for health care providers to spend time sitting with Indigenous people, families, and communities.

This multi-faceted approach needs to include a range of strategies, such as: (a) addressing provider practice through establishing education and professional standards, (b) hiring Indigenous staff to 
support access and navigation, and (c) building meaningful relationships and coordinating services between health care staff and Indigenous families, organizations, and communities. Such coordinated efforts can help advance high quality health care for Indigenous people. Health care providers with a background understanding of the health impacts of colonization and who have developed relationships with local Indigenous people can create a foundation for change within the health care system. These internal champions can tackle the negative attitudes and stereotypes that result in poor care and make health care institutions unwelcoming for Indigenous people.

The respondents interviewed confirmed that, although online Indigenous cultural safety training was valuable in raising awareness, they also needed concrete tools and ongoing supports to make the changes in practice to improve the experience of Indigenous patients. Educational institutions and health professional associations could be champions in bringing forward best practices in health professional curricula and competency standards, and in ensuring their members meet basic requirements for culturally safe care. Nursing scholarship has been leading this work for many years. In the 1990s, a Māori nurse educator advanced the concept of cultural safety, which focuses attention on the inequities in power and relationships, and away from cultural difference as a reason for health access barriers (Papps \& Ramsden, 1996). Work in Canada has also advanced culturally safe standards for health care through emphasizing the need to focus on inequitable power relations, discrimination and historical injustices, and seeing the culture of the health care system as the target for transformative change to advance social justice (Browne et al., 2016). The Indigenous Physicians Association of Canada has also provided recommendations and resources for the medical education curriculum, as has the Leaders in Indigenous Medical Education (LIME) network. The Royal College of Physicians and Surgeons of Canada (2013) mapped Indigenous-specific standards onto the CanMeds competency standards for medical education. The Association of Faculties of Medicine in Canada (AFMC, 2019) has recently created a Joint Commitment to Action on Indigenous Health, calling for a new commitment to implement new curricular frameworks that address the multitude of forms of anti-Indigenous racism. Structural changes, such as embedding cultural safety and competency norms in curricula, policies, and protocols, and holding organizations and staff accountable to these protocols are required in order to improve outcomes (Browne et al., 2010; Ramsden, 1993).

Respondents wanted to see training that was tailored to their reality, including education about and with local communities, and specific education and supports tailored to their own unit (e.g., maternity or cancer care). Care providers want to know about other services available for Indigenous people and proposed improved communication between hospitals and community services to ensure Indigenous people had access to coordinated care. Respondents wanted to see change, but they noted that little change happens without mandates. Creating navigation supports, standards for coordinated discharge planning, and adequately resourced community services would ensure continuity of care for Indigenous patients, to get "the right care, at the right time, in the right place" (Ministry of Health and Long-Term Care, 2015, p.1), whether that be in the reserve community or in the city. Following an Indigenous holistic perspective, a comprehensive approach to health and wellness services can be an effective way to overcome the fragmented nature of health services (Eby, 2007; Ramsden, 1993; Scott, 2010). Strategies to meet these goals include applying Indigenous concepts of health and wellness in health care policy and practice, including integrating traditional health and healing knowledge to inform service delivery, and building collaborative models of care between mainstream and Indigenous-focused services (Alliance for Healthier Communities, 2010). As McIntyre et al. (2017) have noted, Indigenous people 
prefer and are more satisfied with help from traditional healers, and so having traditional healers as a valued part of the care team can assist in ensuring Indigenous people are accessing necessary health services. Such an approach could support better patient and health system outcomes by redirecting potential hospitalization and readmissions cases to appropriate community services and providing better management of chronic conditions that prevent the need for acute care. The imperative and growing willingness to address the gaps in understanding and addressing Indigenous health needs creates a window of opportunity for meaningful change within the health care system in Ontario.

\section{Conclusions}

To improve health care access for Indigenous people, there are many initiatives that need to be put into place. Although system navigation and provider training in cultural safety is an important start to this transformative journey, on their own they are insufficient. Services and institutions need to be more welcoming and inclusive. This requires a significant shift in the attitudes, knowledge, and skills of health care providers. In addition, it requires a rethinking of the service delivery approaches within health care to ensure linkages between acute and community-based care. Real change requires processes of accountability and tracking based on feedback from Indigenous people who use those services, so that culturally safe health care is realized in practice, not just rhetoric or policy.

Actions within a health care institution to address access barriers could have a significant impact on the experiences of Indigenous patients. Initiatives such as training that increases awareness of Indigenousspecific determinants of health can change attitudes and improve relationships between Indigenous patients and families and their care providers. Resources with information about local Indigenous health services could result in discharge plans that ensure access to culturally appropriate community-based services. Ongoing supports such as patient navigators can ensure that gaps in knowledge and practices of care providers can be addressed by other experts in the system. These changes in attitudes support the development of new relationships, which in turn create better coordination of care. These simple recommendations suggest that the health care system can and must take on part of the shared responsibility to improve health care access and experiences that ensure Indigenous people feel cared for in a system competent in providing appropriate and culturally safe care.

\section{References}

Aboriginal Women's Health and Healing Research Group. (2005). Annotated bibliography of Aboriginal health and healing research. Vancouver, Canada: Author.

Adelson, N. (2005). The embodiment of inequity: Health disparities in Aboriginal Canada. Canadian Journal of Public Health, 96(Suppl. 2), S45-S61. doi: https://doi.org/10.1007/BF03403702

Allan, B., \& Smylie, J. (2015). First Peoples, second class treatment: The role of racism in the health and well-being of Indigenous Peoples in Canada. Toronto: Wellesley Institute.

Alliance for Healthier Communities. (2010). Our health, our future. Toronto, Canada: Author.

Amir, R. (2018). Cultural genocide in Canada? It happened here. Aboriginal Policy Studies, Х(1), 103 126. doi: https://doi.org/10.5663/aps.v7i1.28804 
Association of Faculties of Medicine in Canada. (AFMC). (2019). Joint commitment to action on Indigenous health. Retrieved from https://afmc.ca/sites/default/files/AFMC\%20Position\% 20Paper\%20JCAIH_EN.pdf

Belanger, Y. (2010). Ways of knowing: An introduction to Native studies in Canada. Toronto, Canada: Nelson Education Ltd.

Benoit, C., Carroll, D., \& Chaudhry, M. (2003). In search of a healing place: Aboriginal women in Vancouver's Downtown Eastside. Journal of Social Science and Medicine, 56(4),821-833. doi: https://doi.org/10.1016/S0277-9536(02)00081-3

Blumenthal, A. \& Sinha, V. (2015). No Jordan's Principle cases in Canada? A review of the administrative response to Jordan's Principle. International Indigenous Policy Journal, 6(1). doi: https://doi.org/10.18584/iipj.2015.6.1.6

Bowen, G. A. (2008). Naturalistic inquiry and the saturation concept: A research note. Qualitative Research, $8(1)$, 137-152. doi: https://doi.org/10.1177/1468794107085301

Braun, K. L., Allison, A., \& Tsark, J. U. (2008). Using community-based research methods to design cancer patient navigation training. Progress in Community Health Partnerships: Research, Education, and Action, 2(4), 329. doi: https://doi.org/10.1353/cpr.0.0037

Braun, V. \& Clarke, V. (2014). What can "thematic analysis" offer health and well-being researchers? International Journal of Qualitative Studies on Health and Well-being, 9, 1-2. doi: https://doi.org/10.3402/qhw.v9.26152

Brian Sinclair Working Group. (2017). Out of sight: A summary of the events leading up to Brian Sinclair's death and the inquest that examined it and the interim recommendations of the Brian Sinclair Working Group. Retrieved from http://ignoredtodeathmanitoba.ca/

Browne, A. J. (2017). Moving beyond description: Closing the health equity gap by redressing racism impacting Indigenous populations. Social Science \& Medicine, 184, 23-26. doi: https://doi.org/10.1016/j.socscimed.2017.04.045

Browne, A. J., \& Smye, V. (2002). A post-colonial analysis of healthcare discourses addressing aboriginal women. Nurse Researcher, 9(3), 28-41. doi: https://doi.org/10.7748/nr2002.04.9.3.28.c6187

Browne, A. J., Smye, V. L., Rodney, P., Tang, S. Y., Mussell, B., \& O'Neil, J. (2010). Access to primary care from the perspective of Aboriginal patients at an urban emergency department. Qualitative Health Research, 21(3), 333-348. doi: https://doi.org/10.1177/1049732310385824

Browne, A. J., Smye, V. \& Varcoe, C. (2005). The relevance of postcolonial theoretical perspectives to research in Aboriginal health. Canadian Journal of Nursing Research, 37(4), 16-37.

Browne, A. J., Varcoe, C., Lavoie, J., Smye, V., Wong, S., Krause, M., \& Fridkin, A. (2016). Enhancing health care equity with Indigenous populations: Evidence-based strategies from an ethnographic 
study. BMC Health Services Research, 16(544), 1-17. doi: https://doi.org/10.1186/s12913016-1707-9

Castleden, H., Sylvestre, P., Martin, D., \& McNally, M. (2015). "I don't think that any peer review committee ... would ever 'get' what I currently do": How institutional metrics for success and merit risk perpetuating the (re)production of colonial relationships in community-based participatory research involving Indigenous Peoples in Canada. The International Indigenous Policy Journal, 6(4). doi: https://doi.org/10.18584/iipj.2015.6.4.2

Chambers, L. \& Burnett. (2017). Jordan's Principle: The struggle to access on-reserve health care for high-needs Indigenous children in Canada. The American Indian Quarterly, 41(2), 101-124. doi: https://doi.org/10.5250/amerindiquar.41.2.0101

Chandler, M., \& Dunlop, W. (2015). Cultural wounds demand cultural medicines. In M. Greenwood, S. de Leeuw, N. Lindsay, \& C. Reading (Eds.), Determinants of Indigenous Peoples' health in Canada ( $1^{\text {st }}$ ed., pp. 78-89). Toronto, Canada: Canadian Scholars' Press.

Cochran, P. A., Marshall, C. A., Garcia-Downing, C., Kendall, E., Cook, D., McCubbin, L., \& Gover, R. M. S. (2008). Indigenous ways of knowing: Implications for participatory research and community. American Journal of Public Health, 98(1), 22-27. doi: https://doi.org/ $\underline{10.2105 / \mathrm{AJPH} .2006 .093641}$

de Leeuw, S., Lindsay, N., \& Greenwood, M. (2015). Introduction: Rethinking determinants of Indigenous Peoples' health in Canada. In M. Greenwood, S. de Leeuw, N. Lindsay, \& C. Reading (Eds.), Determinants of Indigenous Peoples' health in Canada ( $\left.1^{\text {st }} \mathrm{ed}.\right)$. Toronto, Canada: Canadian Scholars' Press.

Dey, I. (1993). Qualitative data analysis. A user-friendly guide for social scientists. London, England: Routledge.

Dion Stout, M. (2015). Atikowisimiyw-ayawin, ascribed health and wellness, to kaskitamasowinmiywayawin, achieved health and wellness: Shifting the paradigm. In M. Greenwood, S. de Leeuw, N. Lindsay, \& C. Reading (Eds.), Determinants of Indigenous Peoples' health in Canada ( ${ }^{\text {st }}$ ed., pp. 143-151). Toronto, Canada: Canadian Scholars' Press.

Eby, D. K. (2007). Primary care at the Alaska Native Medical Centre: A fully deployed "new model" of primary care. International Journal of Circumpolar Health, 66 (Suppl 1), 4-13.

Eby, D. K. (2019, August 20). Community driven healthcare builds trust and reduces costs. Forum for Health Policy. Retrieved from http://healthpolicy.se/2019/05/10/community-drivenhealthcare/

Elo, S., \& Kyngäs, H. (2008). The qualitative content analysis process. Advanced Nursing, 62(1), 107 115. doi: https://doi.org/10.1111/j.1365-2648.2007.04569.x 
Farmer, P. (2004) An anthropology of structural violence. Current Anthropology, 45(3), 305-325. doi: https://doi.org/10.1086/382250

Fohlich, K. L., Ross, N., \& Richmond, C. (2006). Health disparities in Canada today: Some evidence and a theoretical framework. Health Policy, 79(2-3), 132-43. doi: https://doi.org/10.1016/ j.healthpol.2005.12.010

Germove, J. \& Hornosty, J. (2012). Second opinion: An introduction to health sociology. Don Mills: Canada: Oxford University Press.

Government of Canada. (2018). History of Indigenous Peoples, Aboriginal Affairs and Northern Development Canada and the treaty relationship. Retrieved from https://www.aadncaandc.gc.ca/eng/1338907166262/1338907208830

Government of Canada. (2019). Benefits and services under the Non-Insured Health Benefits program. Retrieved from https://www.sac-isc.gc.ca/eng/1572545056418/1572545109296

Government of Canada, Government of Ontario, \& the Nishnawbe Aski Nation. (2017). Charter of Relationship Principles. Retrieved from https://www.canada.ca/en/healthcanada/corporate/transparency/health-agreements/charter-nan.html

Greenwood, M., Leeuw, S. D., Lindsay, N. M., \& Reading, C. (2015). Determinants of Indigenous Peoples' health in Canada: Beyond the social. Toronto, Canada: Canadian Scholars' Press.

Hammod, C., Thomas R., Gifford, W., Poudrier, J., Hamilton, R., Brooks, C., Morrison, T., Scott, T., \& Warner, D. (2017). Cycles of silence: First Nations women overcoming social and historical barriers in supportive cancer care. Psycho-Oncology, 26(2). doi: https://doi.org/ $\underline{10.1002 / \text { pon. } 4335}$

Howse, G. \& Dwyer, J. (2015). Legally invisible: Stewardship for Aboriginal and Torres Strait Islander health. Australian and New Zealand Journal of Public Health, 4O(Suppl. 1), S14-S20. doi: https://doi.org/10.1111/1753-6405.12358

Hsieh, H. F., \& Shannon, S. E. (2005). Three approaches to qualitative content analysis. Qualitative Health Research, 15(9), 1277-1288. doi: https://doi.org/10.1177/1049732305276687

Indian Act (R.S.C., 1985, c. I-5). Retrieved from https://laws-lois.justice.gc.ca/PDF/I-5.pdf

Israel, B., Checkoway, B., Schulz, A., \& Zimmerman, M. (1994). Health education and community empowerment: Conceptualizing and measuring perceptions of individual, organizational and community control. Health Education Quarterly, 21(2), 149-70. doi: https://doi.org/10.1177/ $\underline{109019819402100203}$

Josewski, V. (2012). Analysing 'cultural safety' in mental health policy reform: Lessons from British Columbia, Canada. Critical Public Health, 22(2), 223-234. doi: https://doi.org/10.1080/ $\underline{09581596.2011 .616878}$ 
Kirmayer, L., Simpson, C., \& Cargo, M. (2003). Healing traditions: Culture, community and mental health promotion with Canadian Aboriginal Peoples. Australasian Psychiatry,11(Suppl), 15-23. doi: https://doi.org/10.1046/j.1038-5282.2003.02010.x

Lallo, S. (2014). Health care through the eyes of Canadian Aboriginal women. Nursing for Women's Health, 18(1), 38-46. doi: https://doi.org/10.1111/1751-486X.12092

Lavoie, J. G., Browne, A. J., Varcoe, C., Wong, S., \& Fridkin, A. (2015). Missing pathways to selfgovernance: Aboriginal health policy in British Columbia. The International Indigenous Policy Journal, 6(1), 1-21. doi: https://doi.org/10.18584/iipj.2015.6.1.2

Lavoie, J. G., Kornelsen, D., Wylie, L., Mignone, J., Dwyer, J., Boyer, Y., Boulton, A., \& O’Donnell, K. (2016). Responding to health inequities: Indigenous health system innovations. Global Health, Epidemiology and Genomics, $2016(1)$, e14.

Laycock, A., Walker, D., Harrison, N., \& Brands, J. (2011). Researching Indigenous health: A practical guide for researchers. Retrieved from https://www.lowitja.org.au/page/services/resources/ health-services-and-workforce/workforce/Researching-Indigenous-Health-Guide

Lincoln, Y., \& Guba, E. (1985). Naturalistic inquiry. Beverly Hills, USA: Sage Publications. doi: https://doi.org/10.1016/0147-1767(85)90062-8

Lincoln, Y., Lynam, S. \& Guba, E., (2011). Paradigmatic controversies, contradictions, and emerging confluences, revisited. In N. K. Denzin \& Y. S. Lincoln (Eds.), The SAGE Handbook of Qualitative Research (pp. 97-128). Thousand Oaks, USA: Sage Publications.

Makokis, P., \& Makokis, J. (2015). Miyo-pimatisiwin: Practicing "the good way of life" from the hospital bed to Mother Earth. In M. Greenwood, S. de Leeuw, N. Lindsay, \& C. Reading (Eds.), Determinants of Indigenous Peoples' health in Canada ( $1^{\text {st }}$ ed., pp. 205-218). Toronto, Canada: Canadian Scholars' Press.

Matthews, R. (2019). Health ethics and Indigenous ethnocide. Bioethics, 33(7), 827-834. doi: https://doi.org/10.1111/bioe. 12610

McCallum, M. J. \& Perry, A.(2018). Structures of indifference: An Indigenous life and death in a Canadian city. Winnipeg, Canada: University of Manitoba Press. doi: https://doi.org/10.1080/ $\underline{02722011.2019 .1653694}$

McIntyre, C., Harris, M. G., Baxter, A. J., Leske, S., Diminic, S., Gone, J. P. \& Whiteford, H. (2017). Assessing service use for mental health by Indigenous populations in Australia, Canada, New Zealand and the United States of America: A rapid review of population surveys. Health Research Policy and Systems, 15(67), 1-17. doi: https://doi.org/10.1186/s12961-017-0233-5

Minister of Health (Canada), Minister of Health (British Columbia), \& First Nations Health Society. (2011). British Columbia Tripartite Framework Agreement on First Nation Health 
Governance. Retrieved from www.hc-sc.gc.ca/fniahspnia/alt formats/pdf/pubs/ services/tripartite/framework-accord-cadre-eng.pdf

Ministry of Health and Long-Term Care. (2015). Bringing care home. Retrieved from http://health.gov.on.ca/en/public/programs/ccac/docs/hcc_report.pdf.

National Aboriginal Health Organization. (2003). What First Nations people think about their health and health care: National Aboriginal Health Organization's public opinion poll on Aboriginal health and health care in Canada. Retrieved from http://www.naho.ca/documents/fnc/ english/FNC SummaryofNAHOPoll.pdf

O’Neil, J., Gallagher, J., Wylie, L., Bingham, B., Lavoie, J., Alcock, D., \& Johnson, H.(2016). Transforming First Nations' health governance in British Columbia. International Journal of Health Governance, 21(4), 229-244. doi: https://doi.org/10.1108/IJHG-08-2016-0042 doi: https://doi.org/10.1108/IJHG-08-2016-0042

Papps, E. \& Ramsden, I. (1996). Cultural safety in nursing: The New Zealand experience. International Journal of Qualitative Health Research, 8(5), 491-7. doi: https://doi.org/10.1093/intqhc/ $\underline{8.5 .491}$

Polanco, F., \& Arbour, L. (2015). Type 2 diabetes in Indigenous populations: Why a focus on genetic susceptibility is not enough. In M. Greenwood, S. de Leeuw, N. Lindsay, \& C. Reading (Eds.), Determinants of Indigenous Peoples' health in Canada ( $1^{\text {st }}$ ed., pp. 223-236). Toronto, Canada: Canadian Scholars' Press.

Ramsden, I. (1993). Kawa whakaruruhau: Cultural safety in nursing education in Aotearoa (New Zealand). Nursing Praxis in New Zealand, 8(3), 4-10. doi: https://doi.org/10.26686/ nzaroe.v0i3.1075

Reading, C. (2015). Structural determinants of Aboriginal Peoples' health. In M. Greenwood, S. de Leeuw, N. Lindsay, \& C. Reading (Eds.), Determinants of Indigenous Peoples' health in Canada ( $1^{\text {st }}$ ed., pp. 3-15). Toronto, Canada: Canadian Scholars' Press.

Reading, J. \& Halseth, R. (2013). Pathways to improving well-being for Indigenous Peoples: How living conditions decide health. Prince George, Canada: National Collaborating Centre for Aboriginal Health.

Reading, C. L. \& Wien, F. (2009). Health inequalities and social determinants of Aboriginal Peoples' health. Prince George, Canada: National Collaborating Centre for Aboriginal Health.

Richardson, L. \& Murphy, T. (2018). Bringing reconciliation to healthcare in Canada: Wise practices for healthcare leaders. Toronto, Canada: HealthCareCAN.

Richmond, C., \& Ross, N. (2009). The determinants of First Nation and Inuit health: A critical population health approach. Health and Place, 15, 403-411. doi: https://doi.org/ 10.1016/j.healthplace.2008.07.004 
Rotondi, M. A., O’Campo, P., O’Brien, K., Firestone, M., Wolfe, S. H., Bourgeois, C., \& Smylie, J. K. (2017). Our Health Counts Toronto: Using respondent-driven sampling to unmask census undercounts of an urban Indigenous population in Toronto, ON. BMJ Open, 7(12), e018936. doi: https://doi.org/10.1136/bmjopen-2017-018936

Royal College of Physicians and Surgeons of Canada. (2013). Indigenous health values and principles statement. Ottawa, Canada: Author.

Sandelowski, M. (1995). Sample size in qualitative research. Research in Nursing \& Health, 18, 179-183. doi: https://doi.org/10.1002/nur.4770180211

Sandelowski, M. (2000). Focus on research methods: Whatever happened to qualitative description? Research in Nursing \& Health, 23, 334-340. doi: https://doi.org/10.1002/1098240X(200008)23:4<334::AID-NUR9>3.0.CO;2-G

Scott, S. (2010). Drawing on Indigenous ways of knowing: Reflections from a community evaluator. The Canadian Journal of Program Evaluation, 23(2), 73-92.

Senate Committee on Human Rights. (2009). First Nations Child and Family Caring Society of Canada: Federal government under-funding of children's services on reserves as a risk factor for disadvantage including sexual exploitation. Retrieved from https://fncaringsociety.com/sites/ default/files/docs/SenateCommitteeOnHumanRights_2009.pdf

Senese, L. C., \& Wilson, K. (2013). Aboriginal urbanization and rights in Canada: Examining implications for health. Social Science \& Medicine, 91, 219-228. doi: https://doi.org/ 10.1016/j.socscimed.2013.02.016

Smith, L. T. (2013). Decolonizing methodologies: Research and Indigenous Peoples. London, England: Zed Books Ltd.

Smylie, J. (2000). A guide for health professionals working with Aboriginal Peoples. Journal of the Society of Obstetricians and Gynecologists of Canada, 100, 1-6. doi: https://doi.org/ $\underline{10.1016 / S 0849-5831(16) 31136-3}$

Snyder, M., \& Wilson, K. (2012). Urban Aboriginal mobility in Canada: Examining the association with health care utilization. Social Science \& Medicine, 75(12), 2420-2424. doi: https://doi.org/ 10.1016/j.socscimed.2012.09.020

Standing Committee on Indigenous and Northern Affairs. (2018). The challenges of delivering continuing care in First Nation communities. Ottawa, Canada: House of Commons Canada.

Stewart, S. (2008). Promoting Indigenous mental health: Cultural perspectives on healing from Native counselors in Canada. International Journal of Health Promotion \&Education, 48(2), 49-56. doi: https://doi.org/10.1080/14635240.2008.10708129

Tagalik, S. (2015). Inuit knowledge systems, Elders, and determinants of health: Harmony, balance, and the role of holistic thinking. In M. Greenwood, S. de Leeuw, N. Lindsay, \& C. Reading (Eds.), 
Determinants of Indigenous Peoples' health in Canada ( $1^{\text {st }}$ ed., pp. 25-32). Toronto, Canada: Canadian Scholars' Press.

Truth and Reconciliation Commission of Canada (TRC). (2015). Honouring the truth, reconciling for the future: Summary of the final report of the Truth and Reconciliation Commission of Canada. Retrieved from http://www.trc.ca/websites/trcinstitution/File/2015/Findings/ Exec_Summary_2015_05_31_web_o.pdf

Walter, M., \& Andersen, C. (2013). Indigenous statistics: A quantitative research methodology. Walnut Creek, USA: Left Coast Press.

Warren-Mears, V., Dankovchik, J., Patil, M., \& Fu, R. (2013). Impact of patient navigation on cancer diagnostic resolution among northwest tribal communities. Journal of Cancer Education, 28(1), 109-118. doi: https://doi.org/10.1007/s13187-012-0436-y

Wilson, S. (2008). Research is ceremony: Indigenous research methods. Winnipeg, Canada: Fernwood Publishing.

Whop, L. J., Valery, P. C., Beesley, V. L., Moore, S. P., Lokuge, K., Jacka, C., \& Garvey, G. (2012). Navigating the cancer journey: A review of patient navigator programs for Indigenous cancer patients. Asia-Pacific Journal of Clinical Oncology, 8(4), e89-e96. doi: https://doi.org/ $\underline{10.1111 / \mathrm{j} .1743-7563.2012 .01532 . \mathrm{x}}$

Wylie, L., \& McConkey, S. (2019). Insiders' insight: Discrimination against Indigenous Peoples through the eyes of health care professionals. Journal of Racial and Ethnic Health Disparities, 6, 37-45. doi: https://doi.org/10.1007/s40615-018-0495-9 